\title{
On the Contribution of Some Economic Sectors to Nigeria Gross Domestic Product
}

\author{
Guobadia Emwinloghosa Kenneth ${ }^{1,2^{*}}$, Ibeakuzie Precious Onyedikachi ${ }^{3}$ \\ ${ }^{1}$ Department of Administration, Federal Medical Centre, Asaba, Delta State, Nigeria \\ ${ }^{2}$ Department of Statistics, University of Benin, Benin, Nigeria \\ ${ }^{3}$ Department of Statistics, Nnamdi Azikiwe University, Awka, Nigeria
}

DOI: $10.36348 /$ sb.2021.v07i03.006 $\quad$ | Received: 25.02.2021 | Accepted: 15.03.2021 | Published: 22.03 .2021

*Corresponding author: Guobadia Emwinloghosa Kenneth

\section{Abstract}

The contribution of various sectors to Nigeria's Gross Domestic Product (GDP) was investigated in this report, as well as the creation of a model for forecasting Nigeria's GDP over a 33-year period (1981-2013). Regression analysis and time series analysis were used to analyze data from the Central Bank of Nigeria. The regression results show a positive relationship between the three sectors: Agricultural, Industrial, and Service, with only the Industrial and Service sectors contributing significantly with coefficients of 0.286 and 0.631 , respectively, while the contribution of the Agricultural sector is not significant with a coefficient of -0.039 , implying that the service sector contributes the most. The agricultural sector makes a negligible contribution. A time domain model (fundamental approach) based on the Box Jenkins approach was used to forecast Gross Domestic Product for the period 1981 to 2013 using the ARIMA model in a developing country like Nigeria. The outcome shows an upward trend, and the series' first difference was stationary, indicating that the series was I (1). ARIMA was found to be the best model for explaining the series using expert modelers $(1,1,0)$. The diagnosis on such a model was verified, the error was white noise, there was no serial correlation, and a 10-year forecast was made, indicating that GDP would continue to rise over the forecasted time period.

Keywords: Gross Domestic Product, Time series analysis, ARIMA, Nigeria.

Copyright (C) 2021 The Author(s): This is an open-access article distributed under the terms of the Creative Commons Attribution 4.0 International License (CC BY-NC 4.0) which permits unrestricted use, distribution, and reproduction in any medium for non-commercial use provided the original author and source are credited.

\subsection{INTRODUCTION}

The development of the Nigerian Economy is one that emanated from a monoculture economy beign based purely on the agricultural sector of the economy, therefore making the sector the main stay of the economy [1]. The discovery of the crude oil in (1956) in commercial quantity has however nullified this assertion, since it has relegated the hitherto mainstay of the economy to the background. This makes it rely solely on the fortunes accuring from the proceeds of oil sector for the growth and development of the Nigerian economy. It is however important to note that the various sectors of any economy has a contribution to the development of that economy, this is to say that no matter how small the contribution of any sector, to the national income of that economy, it add up to the aggregate income of the economy and thus contributing directly or indirectly to the gross domestic earning of such economy. The Gross Domestic Product (GDP) is a basic measure of a country's overall economic performance [2]. It is the market value of all final goods and services made within the border of a country in a year and are often positively correlated with the standard of living. GDP is the most frequently used indicator of economic activity and is most often measured annually or quarterly to gauge the growth of a country's economy between one period and another [3]. A country is said to have good economy if its GDP is relatively high. GDP is important in determining if an economy is growing quickly or slowly than the same quarter the year before, it is used to compare the size of economics that is relative growth rate of economies throughout the world [4]. Also for investors, the GDP is used as a means of adjusting their assets location and to decide where the best opportunities lie. The Gross Domestic Product (GDP) of Nigeria is made up of diverse sectors which includes; Agriculture, Industry, Services, etc. Agriculture is one of the dominant sectors of the Nigerian economy. Though since independence, its role in the economy has been on the downward trend 
especially its contribution to GDP. The sector comprises of crops, livestock, fishing and forestry [5]. It involves the cultivation of land, raising and rearing of animal for the purpose of production of food for man, feed for animals and raw materials for industries. It is essential for the expansion of employment opportunities, reducing poverty and improvement of income contribution for speedy industrialization [6-9]. The service sector has been increasing in major activities of the economy. The service sector comprises of transport, communication, utilities, hotel and restaurant, insurance etc. The service sector has major contribution in value added and gross fixed capital formation in Nigeria. It is an important source of revenue for the nation. Employment share in service sector is increasing, people are moving from other economic sectors to service sector. Industrialization is an integral part of development and structural change in any nation [10]. The industrial sector comprises of the crude petroleum and natural gas, solid mineral and the manufacturing industries. History recorded that the industrial sector performance in Nigeria's economic growth is as old as the nation itself. It dates back to the amalgamation of the southern parts of the country in 1914 for the geographical land mass called Nigeria [11]. A number of fiscal and monetary policies together with institutional reform measures have been undertaken since independence. Right from the first national development plan (1962-1968) to the fourth national development plan (1981-1985) rapid industrialization received priority in Nigeria's development objectives.

The multiple regression models can be expressed as follows;

$$
\mathrm{Y}=\beta_{0}+\beta_{1} X_{i 1}+\beta_{2} X_{i 2} \ldots .+\beta_{K} X_{i k}+\varepsilon_{i} \quad \mathrm{i}=1,2, \ldots, \mathrm{n}
$$

Where

$\mathrm{Y}$ is the dependent variable

$X_{1}, X_{2}, \ldots, X_{k}$ are the independent variables

$\beta_{0}, \beta_{1}, \ldots, \beta_{k}$ are the parameters referred to as regression coefficients.

$\varepsilon_{i}$ represents the error which is normally distributed with mean 0 and variance $\delta^{2} I$

In matrix notation the model in Equation 3.1 can be written as; $Y=\mathrm{X} \beta+\varepsilon$

Where:

$$
\mathrm{Y}=\left[\begin{array}{c}
y_{1} \\
y_{2} \\
\cdot \\
: \\
y_{p}
\end{array}\right] \quad \mathrm{X}=\left[\begin{array}{ccccc}
1 & x_{11} & x_{12} & \ldots & x_{1 k} \\
1 & x_{21} & x_{22} & \ldots & x_{2 k} \\
: & : & : & : & : \\
: & . & . & . & . \\
1 & x_{n 1} & x_{n 2} & . . & x_{n k}
\end{array}\right] \beta=\left[\begin{array}{c}
\beta_{0} \\
\beta_{1} \\
\cdot \\
: \\
\beta_{p}
\end{array}\right] \quad \varepsilon=\left[\begin{array}{c}
\varepsilon_{1} \\
\varepsilon_{2} \\
\cdot \\
\vdots \\
\varepsilon_{p}
\end{array}\right]
$$

The least square estimate of the multiple regressions coefficients is given as:

$$
\hat{\beta}=\left(X^{\prime} X\right)^{-1} X^{\prime} Y
$$

\subsection{Time Series Analysis}

A time series is a sequence of observations that are arranged according to the time of their outcome. Spiegel and Larry (1980) defines it as a set of observation that is obtained at regular periods of time. It is a set of observations generated sequentially in time. There are obviously numerous reasons to record and analyze the data of a time series. Among these is the wish to gain a better understanding of the data generating mechanism, the production of future values 
or the optimal control of a system. In statistical literature, time series refers to that body of principals and techniques which deals with analysis of observed data $X_{t}, t=1,2, \ldots, n[12-14]$.

Some fundamental concepts in the theory of time series models include the following:

\section{Stochastic Processes}

A statistical phenomenon that evolves in time according to probabilistic laws is called a stochastic process. A sequence of random variables $\left\{Y_{t}: t=\right.$ $0, \pm 1, \pm 2, \ldots\}$ is called a stochastic process and serves as a model for an observed time series.

\section{Stationary and Non- Stationary Stochastic Model}

An important class of stochastic models for describing time series, which has received a great deal of attention is the so called stationary models, which assumes that the process remains in equilibrium about a constant mean level. Specifically, a process $Y_{t}$ is said to be strictly stationary if the joint distribution of $\mathrm{Y}_{\mathrm{t} 1}, \mathrm{Y}_{\mathrm{t} 2}, \ldots, \mathrm{Y}_{\mathrm{tn}}$ is the same as the joint distribution of $Y_{t 1-k}, Y_{t 2-k}, \ldots, Y_{t n-k}$ for all choices of time points $t_{1}, t_{2}, \ldots, t_{n}$ and all choices of time lag $k$ [15].

A non-stationary time series implies that the process has no constant mean, non-stationary time series can be stationarized by a suitable degree of differencing.

\section{Autoregressive Models}

A stochastic process $Y_{t}, t \in Z$ is said to be an autoregressive process of order $p$, denoted by AR (p) if it satisfies the difference equation

$$
\begin{aligned}
Y_{t}=\sum_{j=1}^{p} \phi_{j} Y_{t-j} & +e_{t} \\
Y_{t} & =\phi_{1} Y_{t-1}+\phi_{2} Y_{t-2}+\cdots+\phi_{p} Y_{t-p}+e_{t}
\end{aligned}
$$

Where $\phi_{1}, \ldots, \phi_{\mathrm{p}}$ are constant and $\mathrm{e}_{\mathrm{t}} \sim \mathrm{N}\left(0, \delta^{2}\right)$ is a white noise process [16].

\section{Moving Average Models}

A stochastic process $Y_{t}, t \in Z$ is said to be a moving average process of order $q$, denoted by MA(q) if it satisfies the difference equation

$$
\begin{aligned}
Y_{t}=\sum_{j=1}^{q} \theta_{j} Y_{t-j} & +e_{t} \\
Y_{t} & =\theta_{1} Y_{t-1}+\theta_{2} Y_{t-2}+\cdots+\theta_{q} Y_{t-q}+e_{t}
\end{aligned}
$$

Where $\theta_{1}, \ldots, \theta_{\mathrm{q}}$ are constant and $\mathrm{e}_{\mathrm{t}} \sim \mathrm{N}\left(0, \delta^{2}\right)$ is a white noise process.

\section{Autoregressive Moving Average}

A stochastic process $Y_{t}, t \in Z$ is said to be an autoregressive moving average process of order $p$ and $q$, denoted by $\operatorname{ARMA}(p, q)$ if it satisfies the difference equation

$$
\mathrm{Y}_{\mathrm{t}}=\phi_{1} \mathrm{Y}_{\mathrm{t}-1}+\phi_{2} \mathrm{Y}_{\mathrm{t}-2}+\cdots+\phi_{\mathrm{p}} \mathrm{Y}_{\mathrm{t}-\mathrm{p}}+\mathrm{e}_{\mathrm{t}}-\theta_{1} \mathrm{Y}_{\mathrm{t}-1}-\theta_{2} \mathrm{Y}_{\mathrm{t}-2}-\cdots-\theta_{\mathrm{q}} \mathrm{Y}_{\mathrm{t}-\mathrm{q}}
$$

Where $\phi_{1}, \ldots, \phi_{\mathrm{p}}$ and $\theta_{1}, \ldots, \theta_{\mathrm{q}}$ are constant and $\mathrm{e}_{\mathrm{t}} \sim \mathrm{N}\left(0, \delta^{2}\right)$ is a white noise process.

\section{Autoregressive Integrated Moving Average}

A stochastic process $Y_{t}, t \in Z$ is said to be an autoregressive integrated moving average process of order $p, d$ and $\mathrm{q}$, denoted by ARIMA (p, d, q) if it satisfies the difference equation

$$
\phi(B)(1-B)^{d} X_{t}=\theta(B) e_{t}
$$

Where $\phi(B)$ and $\theta(B)$ are polynomials of orders $p$ and $q$ respectively, $d$ is the order of non- seasonal differencing and $\mathrm{e}_{\mathrm{t}}$ is a white noise process

\section{Autocorrelation}

Given $n$ observations $X_{1}, X_{2}, \ldots, X_{n}$ on a discrete time series we can form ( $\left.n-1\right)$ pairs of observations namely $\left(X_{1} X_{2}\right),\left(X_{2} X_{3}\right), \ldots,\left(X_{n-1} X_{n}\right)$. The autocorrelation coefficient is given by:

$$
\rho_{k}=\frac{\sum_{t=1}^{n}\left(X_{t}-\bar{X}\right)\left(X_{t+k}-\bar{X}\right)}{\sum_{t=1}^{n}\left(X_{t}-\bar{X}\right)^{2}} \quad \text { Where } \bar{X}=\frac{1}{n} \sum_{t=1}^{n} X_{t}
$$


Guobadia Emwinloghosa Kenneth \& Ibeakuzie Precious Onyedikachi., Sch Bull, Mar, 2021; 7(3): 49-59

This is called the autocorrelation at lag $\mathrm{k}$

\section{Partial Autocorrelation}

The partial autocorrelation function $(\mathrm{PACF})$ is the partial correlation coefficients between the series and lags of itself over time.

\section{Lag}

The lag operator is denoted by L. It shifts a time series so that the shifted time series lags one time unit behind. This is shown as
$(L Y)_{t}=Y_{t-1}$

\subsection{Data Sources and Limitation}

The data used for this study is a secondary data collected from CBN statistical bulletin on gross domestic product of some economic sectors; agriculture, industry and services at 1990 constant basic prices (N'Billion).

Table-1: GDP and its various sectors

\begin{tabular}{|c|c|c|c|c|}
\hline YEAR & Industrial sector & Service sector & Agricultural sector & GDP \\
\hline 1988 & 89.45 & 34.50 & 84.43 & 251.05 \\
\hline 1989 & 83.61 & 33.84 & 86.49 & 246.73 \\
\hline 1990 & 72.26 & 31.63 & 85.28 & 230.38 \\
\hline 1991 & 78.15 & 30.65 & 80.98 & 227.25 \\
\hline 1992 & 28.04 & 39.36 & 26.77 & 253.01 \\
\hline 1993 & 83.09 & 29.28 & 28.04 & 257.78 \\
\hline 1994 & 81.83 & 30.14 & 39.36 & 256.00 \\
\hline 1995 & 85.41 & 31.45 & 58.08 & 275.41 \\
\hline 1996 & 94.24 & 34.51 & 69.92 & 295.09 \\
\hline 1997 & 125.66 & 32.64 & 84.59 & 328.61 \\
\hline 1998 & 108.40 & 40.73 & 129.61 & 328.64 \\
\hline 1999 & 109.99 & 43.12 & 132.70 & 337.29 \\
\hline 2000 & 109.64 & 44.61 & 135.19 & 342.54 \\
\hline 2001 & 107.04 & 46.19 & 106.68 & 345.23 \\
\hline 2002 & 108.45 & 47.10 & 113.50 & 352.65 \\
\hline 2003 & 115.28 & 33.83 & 149.51 & 367.22 \\
\hline 2004 & 116.87 & 50.14 & 155.93 & 377.83 \\
\hline 2005 & 118.15 & 59.17 & 162.25 & 388.47 \\
\hline 2006 & 110.85 & 53.28 & 170.81 & 393.11 \\
\hline 2007 & 122.06 & 55.18 & 135.12 & 412.33 \\
\hline 2008 & 128.74 & 59.17 & 182.66 & 431.78 \\
\hline 2009 & 123.91 & 72.46 & 190.37 & 451.79 \\
\hline 2010 & 150.25 & 72.75 & 203.01 & 495.01 \\
\hline 2011 & 156.49 & 79.18 & 216.21 & 527.58 \\
\hline 2012 & 159.16 & 85.48 & 231.46 & 561.93 \\
\hline 2013 & 155.17 & 93.33 & 248.60 & 595.82 \\
\hline 2014 & 151.70 & 102.62 & 266.48 & 634.25 \\
\hline 2015 & 146.52 & 117.00 & 283.18 & 672.24 \\
\hline 2016 & 149.49 & 130.44 & 299.82 & 718.98 \\
\hline 2017 & 158.19 & 145.07 & 317.28 & 776.33 \\
\hline 2018 & 161.12 & 161.52 & 335.18 & 834.00 \\
\hline 2019 & 162.99 & 177.05 & 348.49 & 888.89 \\
\hline 2020 & 165.82 & 193.15 & 365.28 & 950.11 \\
\hline
\end{tabular}

\subsection{DATA ANALYSIS}

The analysis on the contribution of some economic sectors to GDP is done using multiple regression analysis.

The summary of the model is presented in table 4.1

Table-2: Model Summary

\begin{tabular}{|l|l|l|l|l|}
\hline Model & R & R Square & Adjusted R Square & Std. Error of the Estimate \\
\hline 1 & .989 & .978 & .975 & 0.02870 \\
\hline
\end{tabular}


Guobadia Emwinloghosa Kenneth \& Ibeakuzie Precious Onyedikachi., Sch Bull, Mar, 2021; 7(3): 49-59

The value of $\mathrm{R}=0.989$ tells us that there is a high positive relationship between the predictor variables (Agriculture, industry and service sector) and GDP. The value of $R^{2}$ of 0.978 (known as the coefficient of determination) tells us that $98 \%$ of the variation in GDP could be explained by Agriculture, industry and service sector while the remaining $2 \%$ could not be accounted for. The Adjusted $R^{2}$ of 0.975 is close to the $R^{2}$ value of 0.978 meaning that the model is fit for making generalization $[17,18]$.

The SPSS software was used to estimate the parameter for this model and it is displayed below as:

Table-3: Model Parameter

\begin{tabular}{|l|l|l|l|}
\hline \multirow{2}{*}{ Model } & \multicolumn{2}{l|}{ Unstandardized Coefficients } \\
\cline { 3 - 4 } & B & Std. Error \\
\hline \multirow{4}{|c|}{ (Constant) } & 0.995 & 0.087 \\
\cline { 2 - 4 } & Agricultural sector & -0.039 & 0.049 \\
\cline { 2 - 4 } & Industrial sector & 0.286 & 0.069 \\
\cline { 2 - 4 } & Service sector & 0.631 & 0.041 \\
\hline
\end{tabular}

The regression model given in equation 1 is given as:

$$
\begin{aligned}
& G D P=\beta_{0}+\beta_{1}(\text { Agriculture })+\beta_{2}(\text { industry })+\beta_{3}(\text { services })+\varepsilon_{k} \\
& =0.995-0.039(\text { Agriculture })+0.286(\text { industry })+0.631(\text { services })
\end{aligned}
$$

From table 3, it could be observed that for every one billion naira increase in the agricultural sector there is a corresponding decrease of 39 million naira in GDP if all other sectors are under control. Industrial sector also contributes to the GDP; for every one billion naira increase in the industrial sector GDP increases by 286 million naira if all other sectors are under control.
For every one billion naira increase in the service sector, GDP increases by 631 million naira if all other sectors are under control. If there is no increase in any of the three sectors GDP increases by 995 million naira. From the analysis it shows that service sector contributes the most, followed by the industrial sector and the agricultural sector contributes the least.

Table-4: Adequacy of the model

\begin{tabular}{|c|l|l|l|l|l|l|}
\hline \multicolumn{7}{|c|}{ ANOVA } \\
\hline \multicolumn{2}{|c|}{ Model } & Sum of Squares & df & Mean Square & F & Sig. \\
\hline \multirow{2}{*}{1} & Regression & 1.047 & 3 & .349 & 423.546 & .000 \\
\cline { 2 - 8 } & Residual & .024 & 29 & .001 & & \\
\cline { 2 - 7 } & Total & 1.071 & 32 & & & \\
\hline
\end{tabular}

The result from the p-value of the Anova table (Table 4) shows that GDP has been explained by the variables in the model, this shows that the model is adequate. The Significance of the parameter is presented in table 5 .

Table-5: For obtaining the parameter significance

\begin{tabular}{|l|l|l|l|}
\hline Parameter & T-value & P-value & Remark \\
\hline$\beta_{1}=-0.039$ & -0.804 & 0.428 & Non- Significant \\
\hline$\beta_{2}=0.286$ & 4.173 & 0.000 & Significant \\
\hline$\beta_{3}=0.631$ & 15.516 & 0.000 & Significant \\
\hline
\end{tabular}

The p-value in table 4 shows that industrial sector and service sector contributes significantly to GDP while the contribution of the agricultural sector is not significant. The analysis on the modeling and forecasting GDP is done using time series analysis. 


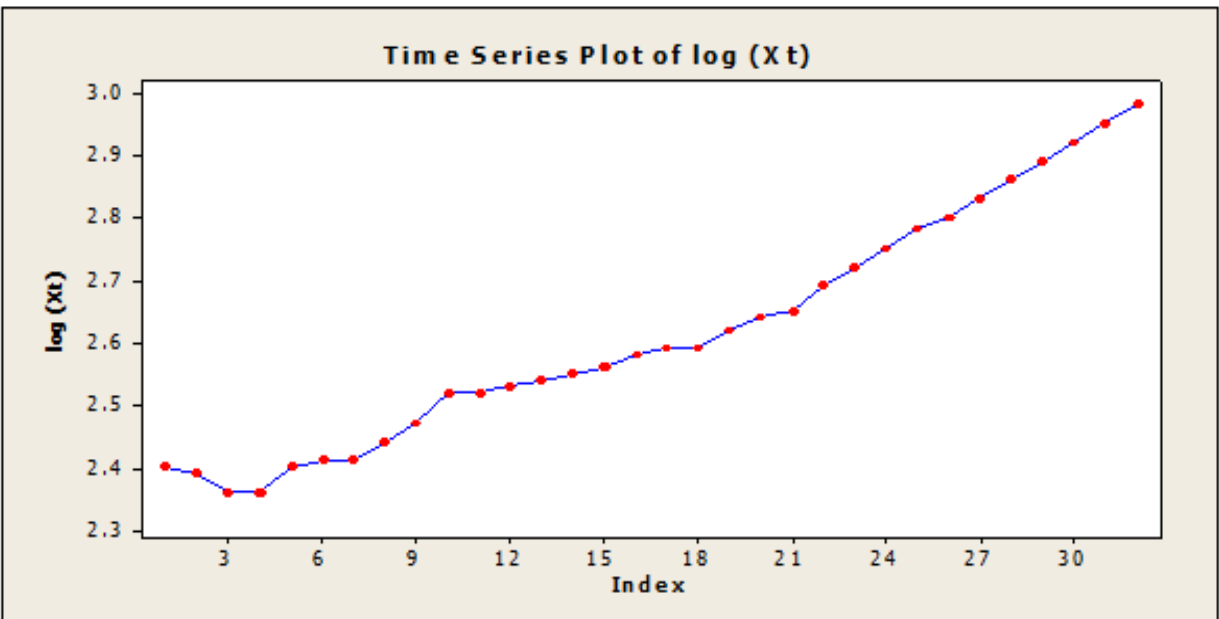

Fig-1: The line graph of $\log \left(X_{t}\right)$

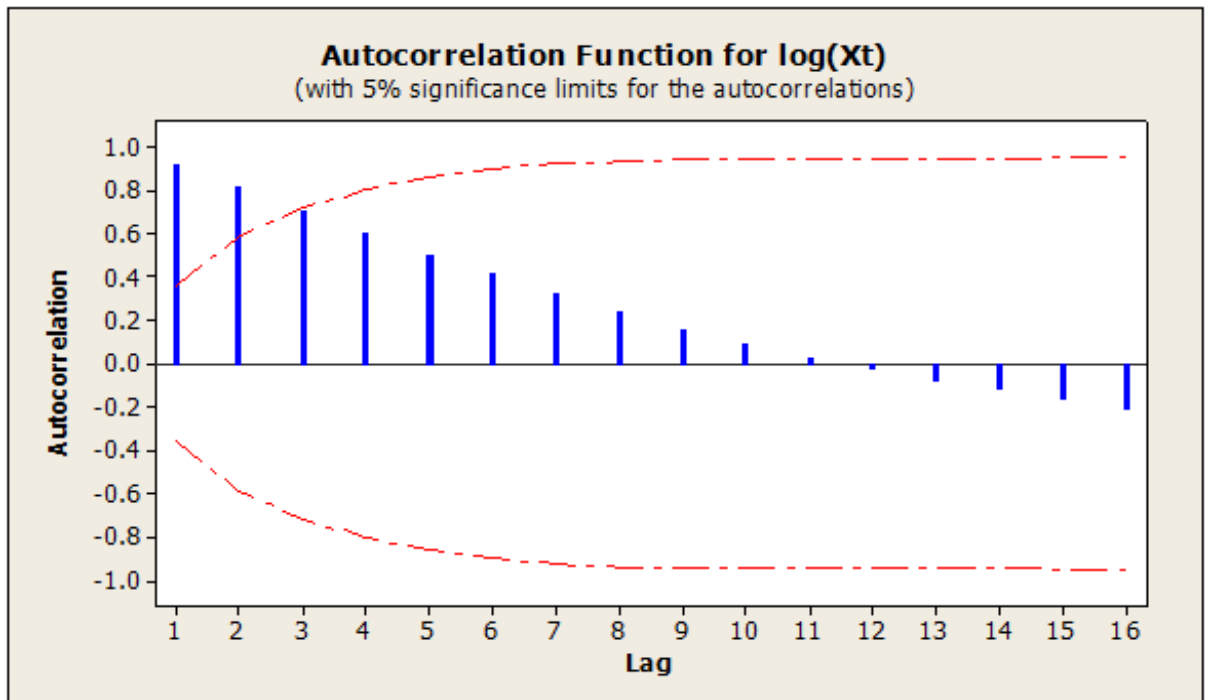

Fig-2: ACF of the Log Transformed GDP Data

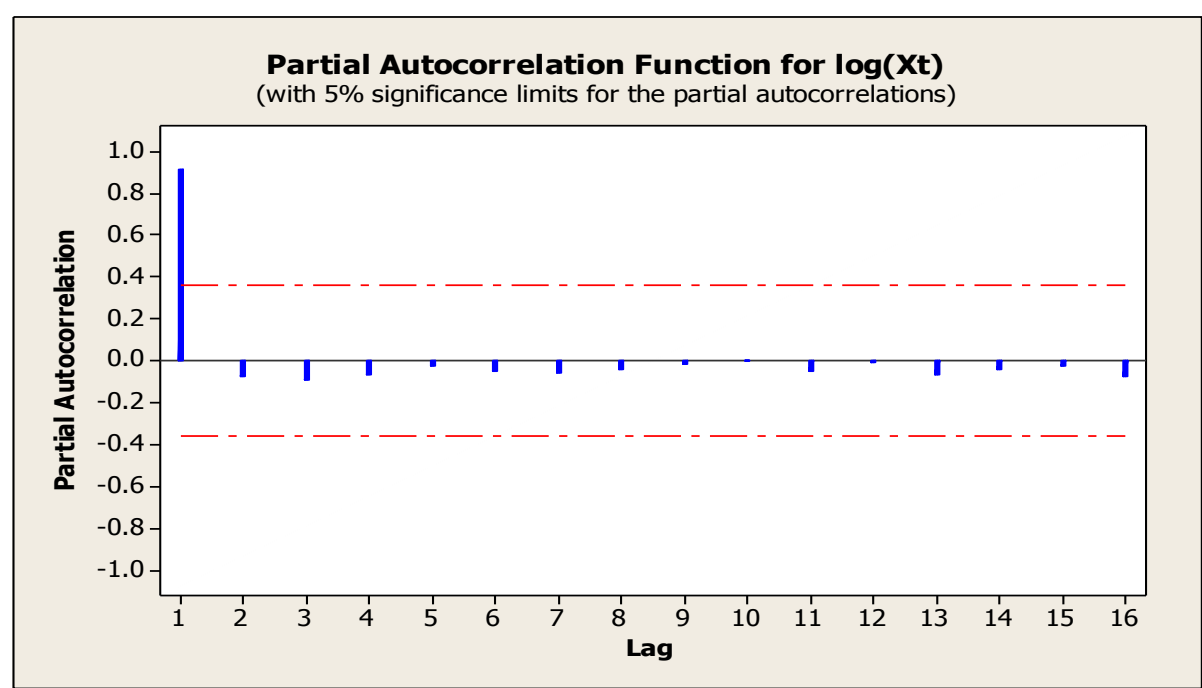

Fig-3: PACF of the Log Transformed GDP Data

From 1 , the graph $\log \left(X_{t}\right)$ is not stationary. The original ACF and PACF plot are found not to be stationary; hence a differencing of the first order is carried out to make the data stationary. 


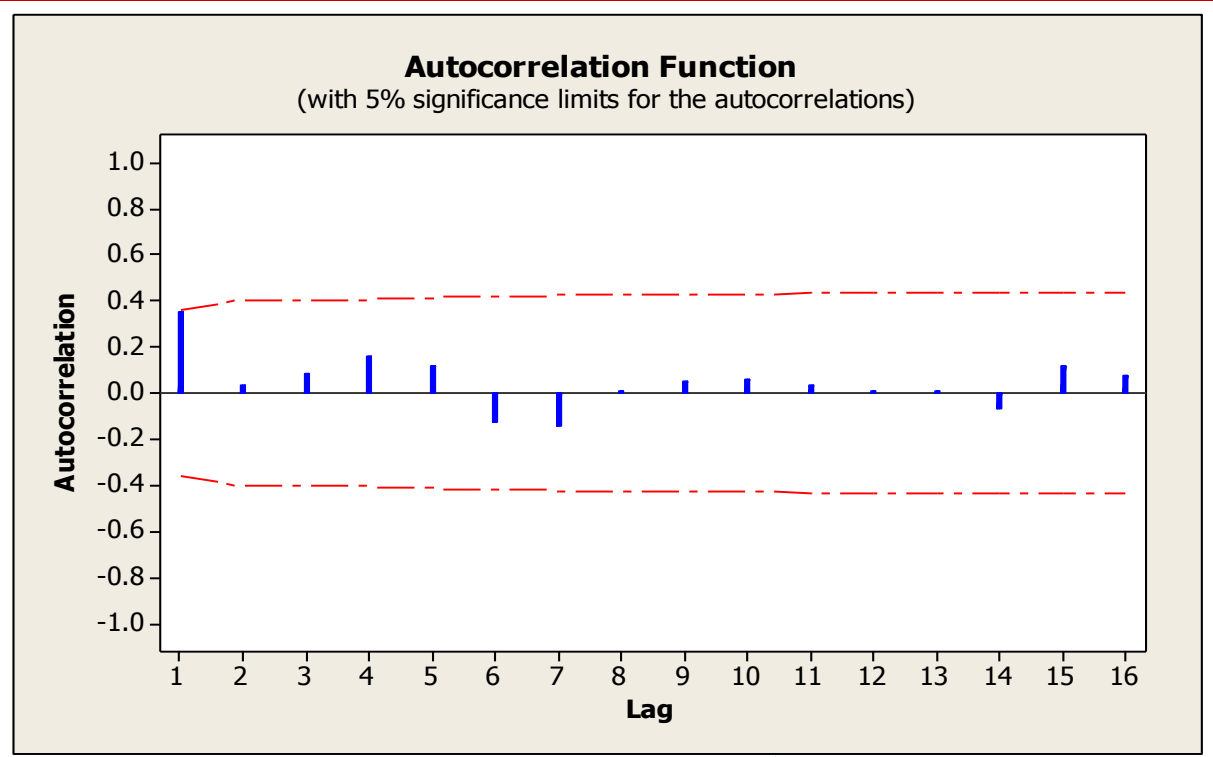

Fig-4: Auto correlation function of the $1^{\text {st }}$ differenced series

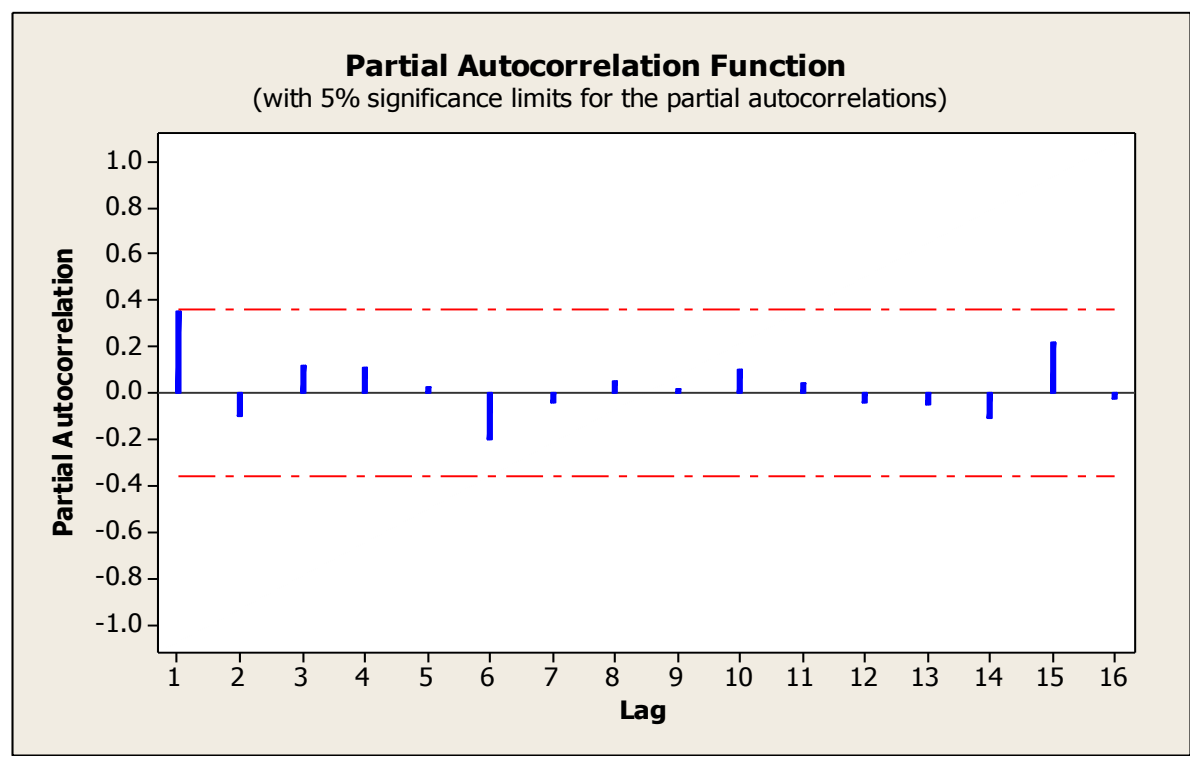

Fig-5: Partial auto correlation function of the $1^{\text {st }}$ differenced series

The first order differencing cuts off after lag 1 as observed in the PACF which indicated an AR of order 1 process. The expert modeler function in SPSS software was used to fit an adequate model for the data and the model fitted is presented in table 5:

\begin{tabular}{|l|l|l|l|}
\hline \multicolumn{2}{|c|}{} & Model Type \\
\hline Model ID & var2 & Model_1 & ARIMA(1,1,0) \\
\hline
\end{tabular}

The model identified can be stated as

$\mathrm{X}_{\mathrm{t}}=\varphi_{0}+\varphi_{1}\left(\mathrm{X}_{\mathrm{t}-1}-\mathrm{X}_{\mathrm{t}-2}\right)+\mathrm{X}_{\mathrm{t}-1}+\varepsilon_{\mathrm{t}}$

After a tentative model has been identified, the parameters of the model will be estimated. The SPSS software was also used to estimate the parameter for this model and it is displayed in table 6 
Guobadia Emwinloghosa Kenneth \& Ibeakuzie Precious Onyedikachi., Sch Bull, Mar, 2021; 7(3): 49-59

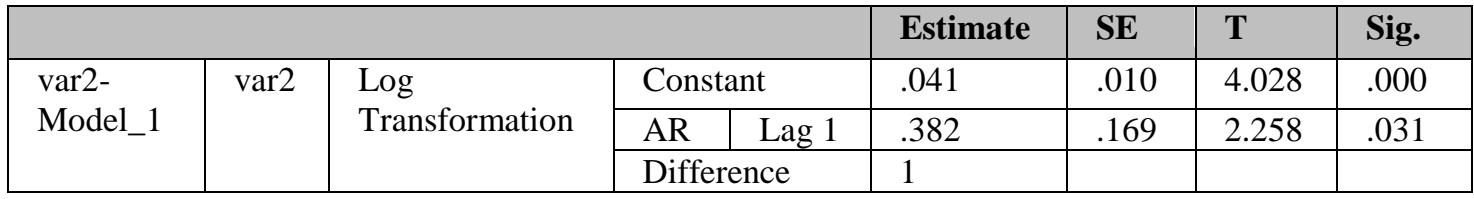

The value $\varphi_{0}$ of in the model is 0.041 , and $\varphi_{1}$ is 0.382 .

We can now state the model as:

$X_{t}=0.041+0.382\left(X_{t-1}-X_{t-2}\right)+X_{t-1}+\varepsilon_{t}$

\subsection{Test of Significance of the Model Parameter}

$H_{0}$ : Model parameter is not significant

$H_{1}$ : Model parameter is significant

Level of significance: $\alpha=0.05$

Decision rule: Reject $H_{0}$ if $\left|t_{c a l}\right|>t_{t a b}$ : otherwise do not reject.

Test statistics: $t_{\text {cal }}=\frac{\widehat{\varphi}}{s e} \sim t_{n-1(\alpha)}$

Where; $\hat{\varphi}=$ estimate and $s e=$ standard error

Calculations

$t_{c a l}=\frac{0.382}{0.169}=2.26$ $t_{t a b}=1.658$

\section{CONCLUSION}

Since $2.26>1.658$ we reject $H_{0}$ and conclude that the model parameter $\hat{\varphi}$ is statistically significant

\subsection{Model Verification}

Since the model fitted in this research work is a tentative one, there is always a need for us to check for the adequacy of the fitted model through diagnostic checking. If the fitted model is adequate enough, it will transform the error components or residuals into white noise process [19-22].

We shall test the diagnostic of this model using the Ljung-Box Q (18) in table 7.

Table-7: Model Statistics

\begin{tabular}{|c|c|c|c|c|c|c|c|}
\hline \multirow[b]{2}{*}{ Model } & \multirow{2}{*}{$\begin{array}{l}\text { Number of } \\
\text { Predictors }\end{array}$} & \multicolumn{2}{|c|}{ Model Fit statistics } & \multicolumn{3}{|c|}{ Ljung-Box Q(18) } & \multirow{2}{*}{$\begin{array}{c}\text { Number of } \\
\text { Outliers }\end{array}$} \\
\hline & & $\begin{array}{l}\text { Stationary R- } \\
\text { squared }\end{array}$ & $\begin{array}{c}\text { Normalized } \\
\text { BIC }\end{array}$ & Statistics & DF & Sig. & \\
\hline $\begin{array}{c}\text { var2- } \\
\text { Model_1 }\end{array}$ & 0 & .131 & 5.234 & 8.215 & 17 & .962 & 0 \\
\hline
\end{tabular}

We observed that from Table 7 that the p-value is 0.962 and we conclude that the model is adequate. The graph of the Autocorrelation and Partial
Autocorrelation of the residuals is shown in Fig 5 and Fig 6.

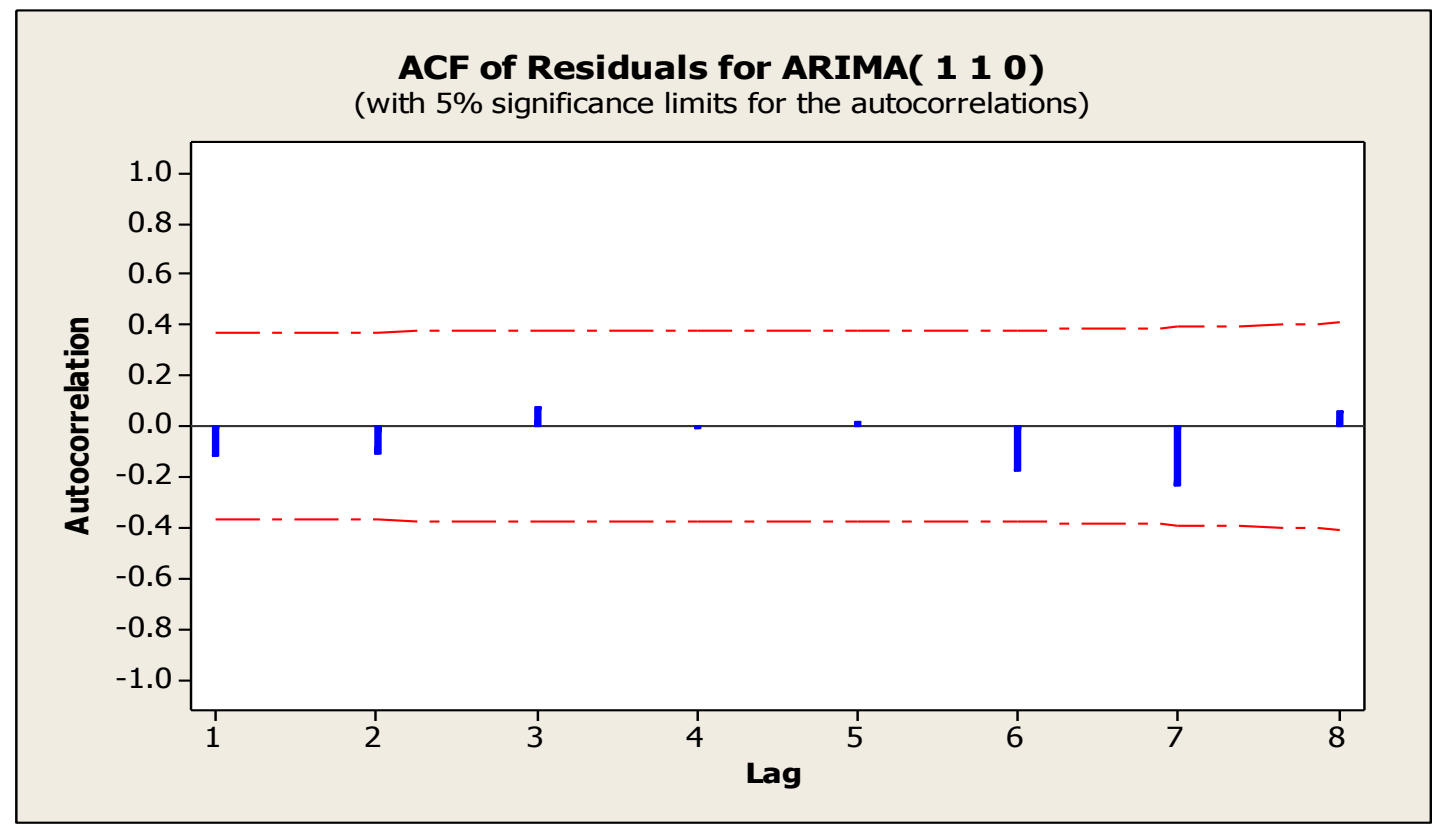

Fig-6: Residual auto correlation function 


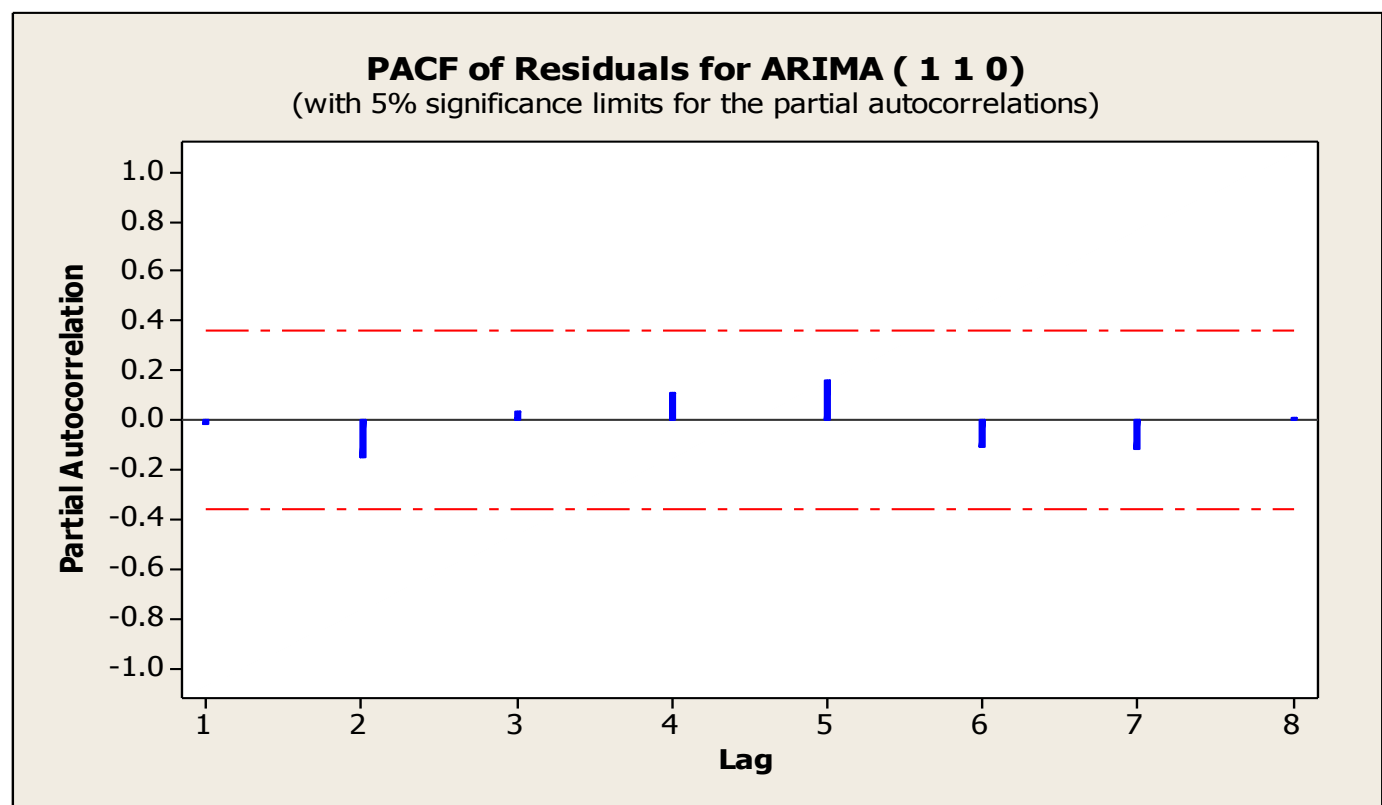

Fig-7: Residual partial auto correlation function

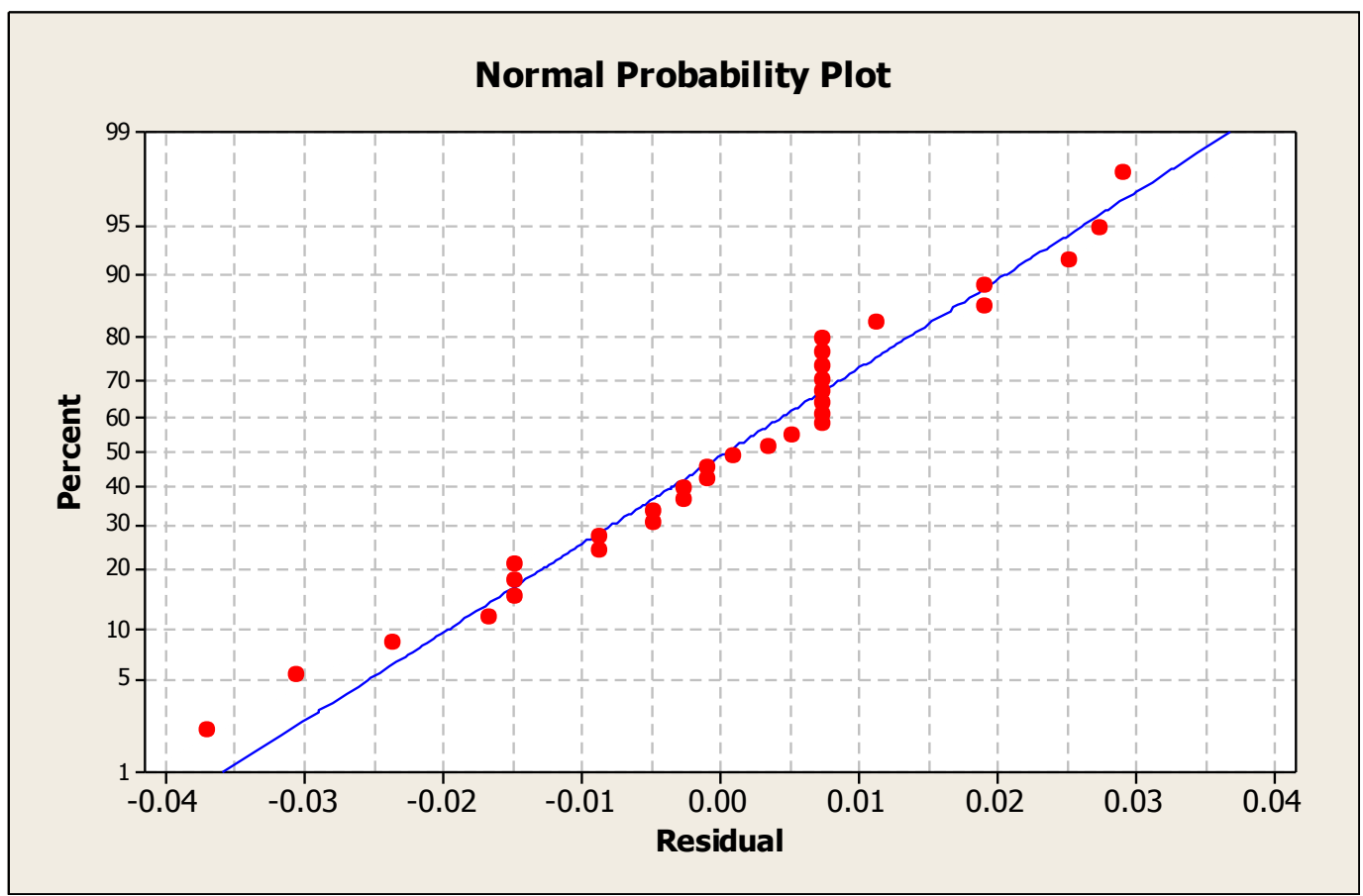

Fig-8: Residual normal probability plot partial

From the graph residual autocorrelation function plotted against the lags, all the observation falls within the pegged limit. It is a confirmation that the model fitted is a good fit. The plot of the residual shows that error is normally distributed [23-25].

\subsection{Forecasting}

The model ARIMA (1 110$)$ above has been subjected to rigorous testing and has been found to be adequate for forecasting. Hence, in this section we would apply our tentative model developed in forecasting. The GDP 1990 constant basic prices for year 2021-2030.

$$
X_{t}=0.041+0.382\left(X_{t-1}-X_{t-2}\right)+X_{t-1}+\varepsilon_{t}
$$

The forecast was carried out on a 95 percent confidence limit and it is displayed on the table below: 
Guobadia Emwinloghosa Kenneth \& Ibeakuzie Precious Onyedikachi., Sch Bull, Mar, 2021; 7(3): 49-59

Table-8: Forecast table

\begin{tabular}{|l|l|l|l|}
\hline PERIOD & FORECAST & LOWER LIMIT & UPPER LIMIT \\
\hline 2021 & 1000.25 & 928.36 & 1076.29 \\
\hline 2022 & 1047.30 & 921.43 & 1185.82 \\
\hline 2023 & 1094.33 & 920.68 & 1291.82 \\
\hline 2024 & 1142.60 & 925.25 & 1396.72 \\
\hline 2025 & 1192.64 & 934 & 1502.42 \\
\hline 2026 & 1244.73 & 946.01 & 1610.25 \\
\hline 2027 & 1299.05 & 960.65 & 1721.20 \\
\hline 2028 & 1355.71 & 977.50 & 1836.00 \\
\hline 2029 & 1414.84 & 996.27 & 1955.25 \\
\hline 2030 & 1476.54 & 1016.76 & 2079.44 \\
\hline
\end{tabular}

\subsection{CONCLUSION}

The regression results shows that the three sectors; Agricultural sector, Industrial sector and Service sector has a positive relationship and only the Industrial sector and the Service sector contributes significantly with a coefficient of $0.286,0.631$ while the contribution of the Agricultural sector is not significant with a coefficient of -0.039 . The F- test shows that the overall model is significant with a p-value of 0.000 . The test for parameter significant also revealed that the agricultural sector is not statistically significant. The modeling cycle for the Box -Jenkins approach was in three stages, the first stage was model identification stage, where the series was non- stationary base on the result provided by the ACF and time plot. It was found out that the series was stationary at the $1^{\text {st }}$ difference. The second stage was the model estimation, where the parameters conforms to the stationary conditions (less than one) and finally the third stage was model diagnosis where the errors derived from the model was normally distributed and random (no time dependence). From the result obtained it can be seen that only the industrial and service sector sectors of the economy contributes significantly to the Gross Domestic Product of Nigeria while the contribution of the agricultural sector is not significant. This implies that service sector contributes the most with 286 million naira followed by the industrial sector with 631 million naira while the agricultural sector does not contribute significantly since it decreases by 39 million naira. However the model identified from the time series analysis was ARIMA (1 1 0). From the graph of residual autocorrelation function plotted against the lags, all observation falls within the pegged limit. It is a confirmation that the model fitted is a good fit. From my forecast table (4.2.5), we can see all the prediction made for subsequent years and it also reveals that GDP will continue to appreciate with these forecasted time period.

\section{REFERENCE}

1. Amadi, I. U., \& Aboko, S. I. (2013). The fitting of ARIMA model in forecasting Nigeria Gross Domestic Product. Journal of Physical Science and Innovation, 5(2).
2. Anyanwu, S. O., Offor, U. S., Adesope, O. M., \& Ibekwe, U. C. (2013). Structure and growth of the gross domestic product (1960-2008): Implications for small-scale enterprises in Nigeria. Global Advanced Research Journal of Management and Business Studies, 2(6), 342-348.

3. Bawa, S., \& Mohammed, J. A. (2007). Natural resource abundance and economic growth in Nigeria. Central Bank of Nigeria Economic Review, 45(3), 25-32.

4. Ekaette, U. J. (2009). Development challenges in the Niger Delta and the implications for the Nigerian Economy. Port Harcourt: PANAM Nigeria Publishers.

5. Kenneth, G. E., \& Onyedikachi, I. P. (2021). Short Term Modeling of the Nigerian Naira/United States Dollar Exchange Rate Using ARIMA Model. Sch J Phys Math Stat, 1, 8-13.

6. Ekpo, A. H., \& Umoh, O. J. (2012). An overview of the Nigerian economic growth and development. Daily Newspaper on Saturday July, 14, 2012.

7. Hussain, A., \& Khan, A. Q. (2011). Relationship between Agriculture and GDP growth rates in Pakistan: An Econometric analysis (19612007). Academic Research International, 1(2), 322.

8. Osuji, G. A., Obubu, M., \& Nwosu, C. A. (2016). Stock investment decision in Nigeria; A PC Approach. World, 2(1).

9. C Nwokike, C., C Offorha, B., Maxwell, O., O Uche-Ikonne, O., \& C Onwuegbulam, C. (2020). ARIMA modelling of neonatal mortality in Abia State of Nigeria. Asian Journal of probability and Statistics, 54-62.

10. Farooq, M. U., Sabir, H. M., Tahir, S. H., Rasheed, M. K., \& Scholar, M. P. (2013). Key factors affecting GDP in Pakistan over the period 19752011. J. Econ. Sustain. Dev, 4, 142-149.

11. Kongsamut, P., Rebelo, S., \& Danyang, X. (2001). Beyond Balanced Growth. IMF Working Paper, $\mathrm{WP} / 01 / 85$.

12. Lawal, W.A. (2011). An analysis of government spending on agricultural sector and its contribution to GDP in Nigeria. International Journal of Business and Social Science, 2(20): 244-250. 
13. Linden, M., \& Mahmood, T. (2007). Long run relationships between sector shares and economic growth: A panel data analysis of the Schengen region.

14. Izuchukwu, O. O. (2011). Analysis of the contribution of agricultural sector on the Nigerian economic development. World review of business research, 1(1), 191-200.

15. Okereke, O. E., \& Bernard, C. B. (2014). Forecasting Gross Domestic Product In Nigeria Using Box-Jenkins Methodology. Journal of Statistical and Econometric methods, 3(4), 33-46.

16. Rahman, M. M., Rahman, M. S., \& Hai-Bing, W. U. (2011). Time series analysis of causal relationship among GDP, agricultural, industrial and service sector growth in Bangladesh. ChinaUSA Business Review, 10(1).

17. Nazish, A. R., Iqbal, A., \& Ramzan, M. (2013). Impact of agriculture, manufacturing and service industry on the GDP growth of Pakistan. Interdisciplinary Journal of Contemporary Research in Business, 5(4), 727734.

18. Suleiman, G. P., \& Aminu, U. (2010). Analysis of the contribution of the three Key sectors (Agriculture, Petroleum and Manufacturing sectors) of the Nigerian economy. Journal of Management Studies Faculty of Management Sciences. Usman Danfodio University, Sokoto.

19. Uddin, M. M. M. (2015). Causal relationship between agriculture, industry and services sector for GDP growth in Bangladesh: An econometric investigation. Journal of Poverty, Investment and Development, 8.

20. Ukeje, E. U. (2003). Employment creation through small and medium scale enterprises: Country Experiences. CBN Bullion, 27(4).

21. Umaru, A., \& Zubairu, A. A. (2012). An Empirical Analysis of the Contribution of Agriculture and Petroleum Sector to the Growth and Development of the Nigerian Economy from 19602010. International Journal of Social Sciences \& Education, 2(4).

22. Wang, X. Z. Wu, S. L., \& Gao, F. (2010). The relationship between economic growth and agricultural growth: The case of China. Paper presented at International Conference on EBusiness and E-Government (ICEE), Guanghou, China.

23. Yakubu, M., Shehu, L., \& Mukhtar. G. (2013). Modeling and Forecasting of Nigeria Crude Oil Prices Using Box-Jenkins Technique. Journal of Physical Science and Innovation, 5(2): 50-59.

24. Maxwell, O., Happiness, O.I., Alice, U.C., \& Chinedu, I.U. (2018). An Empirical Assessment of the impact of Nigerian All Share Index, Market Capitalization, and Number of Equities on Gross Domestic Product. Open Journal of Statistics, 8, 584-602. https://doi.org/10.4236/ojs.2018.83038

25. Uche-Ikonne Okezie, O., Offorha Bright, C., \& Ukomah Henry, I. (2020). Forecasting monthly prices of gold using artificial neural network. Journal of Statistical and Econometric Methods, 9(3), 19-28. 